\title{
REDES SOCIAIS NA INTERNET E APRENDIZAGEM DE LÍNGUAS
}

\author{
SOCIAL MEDIA AND LANGUAGE LEARNING
}

\author{
Rodrigo Aragão ${ }^{l}$ \\ Iky Anne Dias ${ }^{2}$
}

Resumo: A sociedade atual, onde tudo está interconectado em redes sociais na internet, demanda novas concepções de sociabilidade, de linguagem e de aprendizagem. Nesse contexto, criar condições para o ensino de inglês se constitui em um novo desafio. Nesse trabalho, investigamos como podemos nos apropriar das características das redes sociais na internet enquanto recursos para o ensino de línguas. Argumentamos que elas podem ser utilizadas como instrumento de interação que permite e provoca a aplicação da língua a contextos reais e o desenvolvimento dos multiletramentos.

Palavras-chave: Aprendizagem. Internet. Ensino de línguas.

Abstract: Nowadays, where everything is connected through digital networks and social media, new conceptions of sociability, language and learning are created. In this context, teaching English as an additional language is a challenge. This paper aims at researching how we may use the characteristics of social media as a resource to teach and learn languages. We argue that they can be used as a tool of interaction that allows the use of language in real contexts through multiliteracies practices.

Keywords: E-learning. Internet. Language Studies.

\section{INTRODUÇÃO}

As Tecnologias digitais, em particular as redes sociais na internet, ocupam papel preponderante nas mudanças que tem ocorrido em vários aspectos da vida social contemporânea. Estas tecnologias têm feito emergir novas relações de sociabilidade, de expressões identitárias, de produção de linguagens, e distintas maneiras de se aprender. Nota-se que tudo agora é

\footnotetext{
${ }^{1}$ Universidade Estadual de Santa Cruz (UESC), Ilhéus, Doutor em Linguística (UFMG). Coordenador do grupo de pesquisa FORTE, Professor Adjunto. E-mail: aragaorc@gmail.com

${ }^{2}$ Universidade Estadual de Santa Cruz (UESC), Ilhéus, Mestre em Letras. Pesquisadora do Grupo FORTE. Email: iafdias@uesc.br
} 
compartilhado nas redes digitais, num processo exponencial de criação e construção conjunta de conhecimentos. Estudos tem sugerido distintas formas de como a escola pode apropriar-se dos potenciais das redes sociais na internet para a aprendizagem de línguas (ALEXANDRE; PERES, 2011; FARIA, 2010; SILVA, 2013; UMBELINA, 2013). Isto nos impulsiona a expandir neste artigo nossa compreensão do que é uma rede social, suas características, seus elementos constituintes que a definem e suas potencialidades para o ensino e aprendizagem de línguas.

No âmbito do grupo de pesquisa FORTE - Formação, Linguagens e Tecnologias - da Universidade Estadual de Santa Cruz temos trabalhado com a formação dos professores em serviço articulada a formação inicial na Universidade com bolsistas de Iniciação Científica/Tecnológica, de Mestrado Acadêmico e Profissional. Desde o início do nosso trabalho, desenvolvemos pesquisas com foco nos desafios do ensino de línguas na contemporaneidade frente o avanço acelerado de práticas sociais pautadas em tecnologias digitais de comunicação. Nesta seara, discutimos estratégias com os professores para promover ações de ensino/aprendizagem que façam sentido as diversas culturas de seus alunos e os distintos processos de produção de sentido na multimodalidade das linguagens. Aqui trabalhamos ainda maneiras de integrar as tecnologias educacionais normalizadas no contexto escolar (ARAGÃO, 2012) com tecnologias práticas de linguagem de contextos digitais.

Nos embasamos em práticas de pesquisa-ação socialmente situadas (ARAGÃO, 2012; OLIVEIRA, 2012) com escolas das cidades de Ilhéus e Itabuna no sul da Bahia. A partir de 2012 temos desenvolvido ações na busca pelo fortalecimento de redes entre as escolas e as agências formadoras. Neste artigo elaboramos uma reflexão conceitual pautada nas redes sociais e suas características tomando como referência observações e registros em campo feitos durante a etapa inicial de uma pesquisa-ação em uma escola de ensino fundamental da rede estadual em Itabuna.

Assim, de maneira colaborativa com a professora-pesquisadora da escola, sua turma de oitavo ano e nossa ação de pesquisa, desenvolvemos estratégias de ensino que alinhava os conteúdos, atividades e tecnologias, como o livro didático, a lousa, outros equipamentos e o Facebook. O planejamento e execução das aulas se articulam com interações no Clinging, um grupo fechado criado no referido site de redes sociais (RECUERO, 2009) para a relização das 
atividades ao longo do segundo semestre de $2013^{3}$. Dito em outras palavras, a meta era explorar os recursos disponíveis na escola e suas ações situadas, conectado a outras formas de conhecer e com o próprio viver na linguagem.

\section{REDES SOCIAIS}

Sempre estivemos conectados em rede, afinal essa é a forma de organização da própria natureza (BARABÁSI, 2009), contudo há pouco tempo temos dedicado mais tempo para pesquisar e compreender como sua dinâmica se desenvolve. Musso (2004), por exemplo, faz uma retomada histórica sobre o conceito de redes e explica que tal metáfora, originariamente matemática, e ainda presente nessa ciência, nas pesquisas de informática, inteligência artificial e modelos conexionistas da aprendizagem, tem encontrado espaço em diversas áreas do conhecimento. Foi a partir de um quebra-cabeça comum na próspera cidade de Könisberg, na Prússia oriental do começo do séc. XVIII: "Pode-se cruzar as sete pontes sem jamais passar pela mesma ponte duas vezes?" que o matemático Leonhard Euler desenvolveu a teoria dos grafos ${ }^{4}$ para provar que não havia solução para o problema (BARABÁSI, 2009).

Segundo Musso (2004), a palavra rede apareceu no séc. XVII, na língua francesa (réseau), relacionada às redes de pesca e de caça, tecidos e cestas. Ainda no mesmo século, o termo foi comparado ao cérebro por Descartes e serviu para descrever o aparelho sanguíneo, as fibras, e o "corpo reticular da pele". No século XVIII, Diderot, em O sonho de d'Alembert, compara o corpo humano a uma teia de aranha, "uma rede que se forma, cresce, se estende, lança uma multidão de fios imperceptíveis" (DIDEROT apud MUSSO, 2004, p. 19) que chegam a toda parte. São as primeiras aproximações do conceito de rede aos sistemas dinâmicos interdependentes.

A grande ruptura do conceito aconteceu na virada para o século seguinte, quando a rede desvinculou-se do corpo e passou a ser vista como algo que pode ser concebido e construí-

\footnotetext{
${ }^{3}$ Como o trabalho envolvia estudantes com idade inferior a 18 anos, decidimos, por questões de segurança, que o Clinging seria um grupo fechado. Nessa configuração, somente os participantes da pesquisa-ação poderiam visualizar e participar do grupo. Embora o fechamento do grupo limitasse as possibilidades interacionais dentro do mesmo, acreditamos que contribuiria para que os estudantes se sentissem mais dispostos e seguros ao interagir em inglês naquele ambiente.

${ }^{4}$ Grafo é um “conjunto de nós conectados por links" (BARABÁSI, 2002, p. 10), uma rede.
} 
do, desmaterializou-se e passou a ser usado pela engenharia. Ainda no século XIX, o filósofo e economista Saint-Simon desenvolveu uma filosofia religiosa, onde o vínculo social se fazia pelo trabalho dos associados aplicado ao planeta inteiro e a construção de redes de comunicação tinha um objetivo de utilidade pública. Após estas considerações, Musso (2004) define a rede como uma estrutura de interconexão instável, composta de elementos em interação (os nós da rede interconectados), cuja dinâmica obedece a alguma regra de funcionamento.

Hoje, o conceito de rede tornou-se uma espécie de chave-mestra ideológica, porque recobre três níveis de significações: em seu ser, ela é uma estrutura composta de elementos em interação; em sua dinâmica, ela é uma estrutura de interconexão instável e transitória; e em sua relação com um sistema complexo, ela é uma estrutura escondida cuja dinâmica supõe-se a explicar o funcionamento do sistema visível. (MUSSO, 2004, p. 32)

Nas tecnologias a rede é a estrutura das telecomunicações, transporte e energia; na biologia entende-se a rede integrada do corpo humano; na física, o estudo dos cristais e sistemas desordenados; e na economia, o estudo das relações internacionais entre atores e modelos teóricos. Nas ciências sociais, a noção de rede serve para definir sistemas de relações ou modos de organização com estruturas bem organizadas em topologias. O conceito de rede se articula ainda a perspectiva sistêmica da cognição proposta por Maturana (ARAGÃO, 2005), para quem na ciência o mesmo mecanismo explicativo deve dar conta de fenômenos diferentes que podem ser observados juntos. Se por um lado a polissemia da noção de rede lança dúvidas sobre a coerência do conceito, prova, em contrapartida, seu poder e complexidade.

A partir dessas premissas, podemos definir rede social como um conjunto de relações interpessoais que vinculam (links) indivíduos (nós) com interesses mútuos. As redes "proporcionam sociabilidade, apoio, informação, um senso de integração" (WELLMAN apud CASTELLS, 2003, p. 105). Apesar de ser uma forma de organização antiga, a rede ganhou nova vida com a internet que garante meios e estratégias para ser produtivo em tempos de rápidas transformações (CASTELLS, 2003, p. 7). Mergulha-nos em fluxos de informações, de imagens, de sons, de dados (MUSSO, 2004). As redes sociais criadas em diversos sites demonstram quanto este espaço é propício para a caracterização de atores sociais e para a formação de laços entre eles, podendo ser apropriados como instrumentos para a aprendizagem segundo os modos de interagir e conhecer da sociedade atual. 


\section{ELEMENTOS CONSTITUINTES DAS REDES SOCIAIS}

\subsection{Atores sociais}

Os atores sociais são o primeiro elemento de uma rede social. São os nós (nodos) da rede que moldam as estruturas sociais por meio das interações. Nas redes sociais na internet, os atores são os perfis (RECUERO, 2009). Assim, o perfil é uma representação do ator, de um "eu” que busca visualização e sociabilidade nas redes sociais digitais. Essas representações constituem representações identitárias múltiplas com pistas da identidade. Por uma questão conceitual, empregaremos o termo usuário para designar os atores apenas quando em sua interação com o sistema. Em concordância com Primo (2007), consideramos o termo inadequado para a comunicação entre as pessoas, pois neste caso quem estaria usando quem? O usuário usa um programa, mas num diálogo ele é um interlocutor, um ator social representado na rede.

As formas como os atores sociais vão representar-se são constituídas pelas ferramentas de comunicação mediada por computador (CMC), a partir das opções oferecidas por cada rede social na internet, que em geral variam de acordo com o objetivo da mesma. O Facebo$o k$, por exemplo, permite que ator social construa seu perfil na rede com foto, uma imagem de capa, acrescente informações profissionais como instituição de formação e local de trabalho, além de indicações de preferências pessoais, como filmes, estilos e personalidades musicais, livros, programas de televisão. As páginas que cada ator curtiu, também ajudam a identificar seus gostos e interesses. Já o Twitter, por ser uma plataforma de comunicação sintética, permite que o ator selecione também uma imagem de perfil, uma imagem de background, indique sua webpage e faça uma curta descrição de si.

Contribui também para a representação do "eu", nos diversos sites, as próprias postagens feitas por cada interagente. As músicas, vídeos, textos que eles escrevem dão pistas de sua personalidade. Podemos assim conhecer mais o que cada ator costuma ouvir, ler, assistir ou ainda produzir. Distinguimos seus interesses, enfim suas características. Os usuários continuamente fazem novas postagens, removem outras, editam seu perfil. Por isso as representações do "eu" na internet estão dentro de um processo, em construção contínua.

Os atores têm necessidade de serem vistos nos ambientes digitais, como se esta fosse uma condição para a sua existência virtual. A este fenômeno Recuero (2009) retomando Sibi- 
lia, chama de imperativo da visibilidade. A visibilidade traz muitas vantagens para o nó. Quanto mais visível (conectado) está o ator, mais chances ele tem de receber informações que circulam na rede e de ter alcance no conteúdo por ele publicado. Um interagente que não se faz notar de certa forma não existe, pois ninguém o conhece, nem o visita. Se ele não cria uma identidade ou deixa de atualizá-la, se ele não se mostra, ele torna-se uma espécie de fantasma da rede. Por isto, a autora afirma que isto é um imperativo não só para a visibilidade, mas também para a sociabilidade na internet.

O imperativo da visibilidade e da sociabilidade nos aponta para a questão da inclusão no universo digital. Especificamente no contexto dessa pesquisa, os perfis de alunos que não têm acesso à internet em outros ambientes, têm muito menos atualizações e conexões em referência àqueles que dispõem do recurso. Isso os torna menos visíveis e tem todas as implicações apresentadas acima. Acrescenta-se ainda o fato de que o aprendiz mais conectado tem mais acesso ao conhecimento que circula na rede, ampliando sua possibilidade de aprendizagem. Daí a necessidade de a escola ser também um espaço para o acesso livre, em que os alunos possam de fato interagir nesses ambientes e usufruir dos diversos benefícios dos mesmos, para além de uma pedagogização ${ }^{5}$ dessas ferramentas.

\subsection{Conexões e laços sociais}

Enquanto os atores são os nós na metáfora de rede, as conexões são constituídas dos laços sociais formados a partir das interações entre esses nós. A interação consiste nas comunicações em múltiplas linguagens entre os atores sociais. Reforçamos também que o computador não está neutro nas interações por ele mediadas, uma vez que cada meio oferece possibilidades e limitações. Sendo assim, o conceito de interação aqui adotado é o de "ação entre" (inter+ação) (PRIMO, 2007) pessoas ou até mesmo entre pessoa e máquina.

Primo (2007) destaca que, embora toda "ação entre" possa ser considerada interação, elas variam em nível qualitativo. Deste modo, ele classifica a interatividade como reativa ou

\footnotetext{
${ }^{5}$ Baseada em Soares, Ribeiro (2012) explica que a pedagogização ocorre quando os acontecimentos sociais se tornam parte dos discursos e práticas escolares. Isso é inerente é inevitável no processo de escolarização do conhecimento. Quando decorre do diálogo real com o que ocorre fora da escola, com o uso das tecnologias para uma educação em tempo integral, por exemplo, borrando os limites impostos pelos muros da instituição, isso é positivo, mas quando isso é feito de forma forçada, ou apenas vestindo uma roupagem nova para velhas tarefas, o resultado não é satisfatório.
} 
mútua. As interações reativas são aquelas pré-determinadas, como o clique no hiperlink que leva sempre a um lugar previsto, mas que ainda deste modo permite relações sociais. São exemplos as ações para adicionar ou seguir contatos, a opção curtir do Facebook, ou a opção adicionar como favorito do Twitter. As interações tornam-se mútuas quando permitem uma negociação e são mais participativas. É o caso, por exemplo, do espaço para recados, comentários e as conversas online.

$\mathrm{Na}$ interação mútua os relacionamentos são recriados continuamente como resultado das ações dos interagentes por meio da comunicação. Ela abre espaço para a escrita propriamente dita do ator social, registrando seu papel de produtor onde os próprios leitores podem indicar caminhos aos demais. Cada interlocutor define a si mesmo e negocia com o outro, num choque de forças em busca de algum consenso. Além de competir, os indivíduos cooperam entre si. Ao compartilharem informações variadas, os atores cooperam e ao defenderem suas singularidades, disputam. Na interação mútua há unidade e diversidade. A comunicação permitida pela interatividade mútua é fundamental para o crescimento e complexificação das relações. Primo (2007) destaca ainda que o diferencial da interação mútua em relação à reativa é a possibilidade de embate de ideias, essencial para a formação de uma sociedade mais justa e, acrescentamos, para os letramentos.

O Facebook possui ferramentas de interação reativa que também permitem a competição e colaboração. Podemos exemplificar com as disputas ocorridas na rede do tipo "curte ou compartilha?", onde as pessoas defendem seus gostos musicais, times de futebol etc. medidos pela popularidade que as opções alcançam no ambiente. Ou ainda os atores podem usar o recurso compartilhar para propagar uma ideia, ou colaborar com uma causa. O compartilhamento é interessante por permitir os dois tipos de interação: a reativa, caso o ator apenas clique e compartilhe, e a mútua, se acrescentar alguma informação à postagem. Consideremos ainda que, ao compartilhar qualquer postagem o ator toma de empréstimo para si aquilo que foi dito, assumindo a voz e fala do outro, num processo de identificação entre os pares. A partir daí, outros têm acesso àquela informação no perfil que o compartilhou e pode se abrir ali um novo espaço de diálogo sobre o que foi publicado.

As interações nas redes sociais digitais podem ainda ser classificadas em síncronas ou assíncronas, de acordo com a simultaneidade das respostas (RECUERO, 2009). Durante o 
andamento da pesquisa, são explorados ambos os tipos de interação, embora a interação assíncrona seja mais presente, devido à facilidade que ela imprime por não exigir dos atores a presença simultânea para a conexão. As interações síncronas só foram usadas para manter o contato entre professor-aluno. Todavia planeja-se a exploração do potencial comunicativo dessas para possibilitar outras comunicações e o uso do inglês, pois promovem a conversação, e conseqüentemente o envolvimento com os pares, facilitando o aprendizado e o fortalecimento dos laços sociais. Neste sentido, dialogamos com estudos que indicam que alunos podem ter mais disposição para se comunicar se fortalecerem os laços de sociabilidade por meio das ferramentas disponibilizadas pelas redes sociais na internet (FARIA, 2010; LETTI, 2013; SILVA, 2013).

O laço é a efetiva conexão entre os atores que estão envolvidos nas interações. "Laços são formas mais institucionalizadas de conexão, constituídos no tempo e através da interação social" (RECUERO, 2009, p.38). Resultam da sedimentação das relações estabelecidas entre os nós. Compreendemos que o padrão das interações vai definir os tipos de laços existentes entre dois ou mais participantes. De acordo com Recuero (2009) os laços podem ser categorizados em fortes e fracos. O primeiro tipo refere-se a laços mais íntimos, de atores que interagem com mais frequência, que criam e mantêm uma relação. As trocas são mais concretas e em maior quantidade. Laços fracos não traduzem intimidade e promovem trocas mais difusas entre os atores.

Castells (2003, p. 107) defende, entretanto que "o fato de a maior parte dos laços mantidos pelas pessoas ser de 'laços fracos' não significa que são desprezíveis. São fontes de informação, de trabalho de desempenho, de comunicação de envolvimento cívico e de divertimento." Os laços fracos servem como base para o desenvolvimento de laços fortes e são essenciais para o alcance dos conteúdos compartilhados na rede. Percebemos inicialmente que os alunos interagem pouco entre si, principalmente aqueles que acessam com menos frequência. Tentamos motivar essas interações marcando-os nas postagens, através da conscientização na sala de aula, e através do chat online.

Os ambientes digitais também facilitaram a desterritorialização dos laços, devido à simplicidade com que é possível criar e manter laços fortes independente da proximidade física, como resultado de um processo histórico de quebra da vinculação necessária entre localidade e sociabilidade. Hoje, para o estudo dos fatos humanos, inclusive os fenômenos da 
linguagem, importa mais que a proximidade física, o espaço prático, isto é, as proximidades efetivas, modificadas pela facilitação das conexões através dos novos meios de comunicação e transporte (LÉVY, 2000). Segundo Castells (2003, p. 107), “a transformação da sociabilidade em sociedades complexas ocorreu com a substituição de comunidades espaciais por redes como formas de sociabilidade".

As pessoas passam então a formar seus laços não mais em sociedades locais, mas movidos por paixões, afinidades partilhadas, hábitos, isto é, "segundo um mapa semântico ou subjetivo dos centros de interesses" (LÉVY, 2000, p. 151) formando o que Castells denomina comunidades de escolha (2003). Embora em nossa pesquisa-ação a formação de laços esteja vinculada à comunidade local que é a escola e mais especificamente a classe, essa conscientização de que pertencemos a uma grande aldeia global na internet é uma das estratégias para envolver os alunos com o inglês, idioma mais comumente utilizado por pessoas de países diferentes na rede. A partir desses laços os grupos constroem o capital social da rede.

\subsection{Capital Social}

Ao longo das últimas décadas, diversos cientistas sociais têm reformulado e/ou adaptado o conceito de capital social. Neste trabalho adotamos o conceito proposto por Recuero (2009), pois a autora se baseou em três dos estudiosos mais citados sobre o assunto (Coleman, Putnam e Bourdieu) para desenvolver uma definição focada nas redes sociais na internet, sendo, portanto muito adequada ao nosso trabalho. Ela define o capital social como um valor constituído a partir das interações entre os atores sociais, isto é, o conjunto de recursos de um determinado grupo que pode ser usufruído por todos os membros, ainda que individualmente. Este capital é construído e negociado entre eles e contribui para o fortalecimento dos laços e sedimentação das conexões. Baseia-se na reciprocidade e é determinado pelo conteúdo das relações sociais. Os recursos que os indivíduos têm acesso na rede se apresentam em dois níveis.

Em primeiro nível, isto é, no aspecto individual, o capital pode ser relacional, normativo ou cognitivo. O recurso relacional constitui-se das relações, laços e trocas entre os indivíduos, enquanto o normativo está associado às normas e valores de um grupo. No grupo 
formado no Facebook foi estabelecida uma única norma: que todo o conteúdo postado estivesse em inglês ou com tradução. No início isso não foi posto claramente, apenas iniciamos as interações na língua alvo. Espontaneamente os estudantes também postaram na língua alvo, todavia duas postagens foram feitas pelos alunos em português, de modo que de um modo delicado indicamos que naquele espaço apenas a língua-alvo deveria ser utilizada. Um deles retirou o conteúdo em português e postou um novo em inglês, embora isso não tenha sido solicitado por nós. O recurso cognitivo está relacionado ao conhecimento e informações colocadas em comum num grupo. Todo conteúdo que circula no grupo criado no Facebook para as interações da pesquisa o Clinging acrescenta o recurso cognitivo, pois contribui para o aprendizado do inglês por meio do contato com os diversos usos do idioma.

Em segundo nível (aspecto coletivo), os recursos podem ser de dois tipos: institucional e de confiança no ambiente social. O segundo nível demonstra maior maturidade e densidade da rede. Quanto mais a parte coletiva do capital social estiver fortalecida, maior a apropriação individual do capital. O recurso institucional refere-se às instituições formais e informais, alto nível de cooperação e coordenação nos grupos. Segundo Antoun (2006), os processos de comunicação mediada por computador (CMC) se emanciparam das formas tradicionais de instituição e governo, e tem em vista a gestão e promoção do bem comum. Na rede formada fica evidente a moderação do grupo pela professora e pela pesquisadora até mesmo pelo alto nível de participação dessas, em contrapartida, os estudantes têm liberdade de publicar o conteúdo que desejarem no grupo, sem necessitar de autorização ou solicitação prévia. Essa liberdade é constantemente reiterada nas aulas e nas interações ciberespaço e é fundamental para o desenvolvimento da criatividade, segundo um modo de pensar aberto (BRASIL, 2006).

A confiança no ambiente social vem da crença na reciprocidade, no consenso e refletese na coletividade, criando valores sociais. A reciprocidade é fundamental para o sucesso desse projeto. Não há sentido nas interações se os alunos não participarem dela. Observamos que inicialmente havia bem poucas interações. À medida que os estudantes foram sendo adicionados ao grupo, o que não aconteceu de uma só vez, pois encontramos diversos empecilhos técnicos que serão relatados posteriormente, a interação dos discentes aumentou. Pela observação do grupo e da sala de aula, detectamos que alguns alunos não interagiam, por não ter perfil no Facebook.

Alguns deles se manifestaram logo no início e utilizamos as primeiras aulas para solu- 
cionar isso, criando contas de e-mail e em seguida, o perfil. Outros, todavia, por constrangimento não se manifestaram. Um aluno colocou um nome de usuário inexistente na lista passada na sala de aula, o que só foi informado após dizermos a ele que não o encontramos no site. Como não imaginávamos a causa, falamos publicamente em sala de aula. Com sua confissão, também pública, o estudante foi zombado por alguns colegas, a respeito de que os corrigimos. Comprometemo-nos a criar perfis (e contas de e-mail) para esses alunos em horários extras, mas não foi possível concluir rapidamente essa tarefa.

Compreendemos então que o capital social é essencial para a manutenção das redes sociais. Em cada ferramenta de rede social na internet o capital social pode ser percebido de uma forma diferente. No caso estudado, constatamos que o capital social está mais presente em primeiro nível, demonstrando que as relações entre os atores não são tão profundas, embora muito significativas. Conhecer o tipo de capital social é importante, pois além de motivar as conexões, ele ajuda a moldar os padrões interacionais que emergem da apropriação dos sites de redes sociais.

\section{Sites de Redes Sociais}

Em tópico anterior, demonstramos como as características dos sites de redes sociais (SRS) proporcionam possibilidades variadas para caracterização de atores sociais. Isso porque cada SRS possui peculiaridades que são apropriadas pelos usuários. A partir de agora, compreenderemos o que vem a ser SRS, os principais traços em comum que o caracterizam como tal, o diferencial de alguns desses softwares sociais inicialmente escolhidos para execução dessa pesquisa e o potencial educativo que os mesmos possuem.

SRS são todos os espaços utilizados para a expressão das redes sociais na internet. Seu diferencial é permitir a articulação das redes e a manutenção de laços offline (RECUERO, 2009). Esses sistemas permitem a construção de uma persona por meio um perfil, como já demonstramos, a interação por meio de comentários etc., além da visibilidade pública das redes por eles suportadas. Não são um elemento totalmente novo, mas um resultado da apropriação de ferramentas de comunicação mediada por computador (CMC). A apropriação a que nos referimos são os usos que os atores fazem desses recursos. Contudo o consumo que dele se faz não é passivo (CERTEAU, 1998), prova disso é apropriação dos SRS com fim de pro- 
mover o aprendizado de idiomas.

Diferente dos ambientes virtuais de aprendizagem (AVA), a finalidade educativa certamente não foi o propósito da criação dos sites utilizados nessa pesquisa, contudo nós, usuários, nos apropriamos deles para esse fim. Cabe destacar que existem SRS desenvolvidos com o propósito de aprendizagem de idiomas. É o caso do LiveMocha, através do qual você aprende autonomamente um idioma ao passo que ensina sua língua materna para falantes de outras línguas. Contudo preferimos focar nessa pesquisa em plataformas que, de modo geral, já são familiares aos alunos, como até mesmo uma maneira de despertá-los para outras potencialidades dos recursos que eles utilizam.

Faria (2010) defende que a aprendizagem de língua estrangeira pode ser conduzida por meio dos AVA, mas também por outros ambientes da web. A autora propõe-se inicialmente a fazer uma comparação entre o TelEduc e o Moodle, AVA amplamente utilizados em todo o mundo, e o Orkut. Após uma breve apresentação de cada plataforma, a autora faz um quadro comparativo entre as mesmas e conclui que para viabilizar a aprendizagem, elas devem propiciar a interação, socialização, adaptação. Assim, embora difira dos AVA por não possuir certos recursos didáticos, o Orkut tem funcionalidades que o habilitam ao uso pedagógico, dentre elas algumas não disponíveis em outros ambientes, além de permitir interação com pares "que não pertencem ao contexto educacional em questão" (FARIA, 2010, p. 24).

Em concordância com Faria (2010), acreditamos que os SRS possuem excelentes recursos para aprendizagem de outros idiomas e para os multiletramentos (em sua dupla multiplicidade: cultural e modal), afinal toda conexão nesses ambientes se dá por meio das diferentes linguagens. Devido à desterritorialização dos laços nas redes sociais, esses sites constituem-se como espaços propícios para o diálogo com as mais diversificadas culturas. É também possível desenvolver as habilidades recomendadas pelas Orientações Curriculares Nacionais para o Ensino de Línguas Estrangeiras (BRASIL, 2006) na aprendizagem de língua estrangeira (leitura, prática escrita e comunicação oral contextualizadas), o que é facilitado pelo próprio caráter multimodal e aberto do hipertexto, contudo como cada uma possui características diferentes, permitem também apropriações diversificadas.

O Facebook, SRS focado nessa pesquisa, por exemplo, possui recursos de compartilhamento de imagens e textos gráficos, que permitem o desenvolvimento das duas primeiras 
habilidades. Os vídeos e o bate-papo por voz permitem a prática da comunicação oral. Pioneiro em permitir o uso de aplicativos, o seu diferencial foi restringir as informações dos atores aos seus pares na rede (RECUERO, 2009). Com o tempo o Facebook permitiu o ingresso de qualquer pessoa em todo o mundo, a partir de 13 anos de idade, e ganhou muitos adeptos na América Latina. No Brasil sua aceitação foi tão grande, que o popular Orkut se tornou uma “cidade fantasma", para fazermos uma menção aos fantasmas da rede de Recuero (2009), pois embora muitos usuários não tenham cancelado seu perfil nessa plataforma, muitos deixaram de atualizá-lo.

A troca de mensagens no "Face" pode ser síncrona ou assíncrona, pública, restrita aos amigos ou ainda privada. Dentre alguns de seus principais recursos estão o status, espaço onde o ator pode postar uma ou mais frases, uma imagem ou ainda iniciar uma enquete; os comentários; a marcação de amigos, através da qual se faz um link para o perfil de um contato que será automaticamente notificado sobre a publicação e pode também ficar exposta no perfil desse, ou ainda conectar à uma página; o botão "curtir" (like, em inglês), de interação reativa que permite ao interagente demonstrar se gostou da postagem feita por alguém, que passou a ser usada também como forma de agradecimento, cordialidade ou apenas para um par deixar claro que visualizou aquela informação, sem precisar usar palavras para isso.

Clicando em compartilhar dada postagem, o ator social replica a mesma em seu própria linha do tempo ${ }^{6}$, em uma página ${ }^{7}$ criada por ele ou ainda em um grupo. Isso torna aquela informação disponível a seus pares, elevando o potencial multiplicador da rede, além de criar um link com o perfil que fez a postagem inicialmente. Como citado, no Facebook é possível também formar grupos que podem ser abertos ou fechados, para os mais variados fins e categorias. É o caso do grupo Clinging, desenvolvido para esta pesquisa.

O Twitter, por sua vez, foi criado dois anos após o Facebook, em março de 2006 por Jack Dorsey, Biz Stone e Evan Williams como um projeto da empresa Odeo, mas só foi lançado em julho (RECUERO, 2009; WIKIPEDIA, 2013). O site funciona num sistema de mi-

\footnotetext{
${ }^{6}$ Refere-se à página pessoal de cada usuário.

${ }^{7}$ Não se trata da página de perfil do ator, mas de uma página à parte criada com um fim específico. Pode representar um artista, uma empresa, ou correr em torno de uma temática ou personagem, pré-existente ou não. A página tem um perfil público para qualquer postagem realizada.
} 
croblogging, tendo como slogan e propósito central a pergunta "What's happening?", que deve ser respondida no máximo em 140 caracteres. Por ter postagens tão curtas, conhecidas como tweets, o Twitter é conhecido como o "SMS da internet". Possui muitos recursos semelhantes em funcionalidade ao Facebook, tais como a opção "Retweet", a qual serve para o mesmo fim que a opção compartilhar; os tweets que são como o status; as mensagens privadas (chamadas aqui de e-mail, possuem caráter essencialmente assíncrono, embora possa como tudo nas redes ser adaptadas), a opção seguir alguém se assemelha em configuração ao "curtir uma página” no Facebook (esse também disponibiliza essa opção “seguir”).

Não existe no Twitter a opção "adicionar amigos", como no Facebook. Cada ator pode seguir os atores que desejar na rede, sem o compromisso de que os pares o sigam de volta. Isso o torna um assinante do conteúdo postado pelo outro, que vai aparecer em sua página inicial quando ele entrar na rede. O conteúdo disponibilizado pelos tweets é sempre público e pode ser visualizado inclusive por quem não tem um perfil no site. Para o ensino, essa possibilidade é muito interessante por facilitar o acesso a conteúdo coeso e atualizado, especialmente no que tange ao inglês, pois possibilita o contato com o idioma quando se segue perfis de falantes da língua-alvo, trazendo novos conhecimentos de ortografia, gramática, sintaxe, vocabulário. Pode ser usado por professores para compartilhar recursos com outros professores, participar de cursos de desenvolvimento profissional em tempo-real e ter atualizações de outras instituições.

A opção "responder" do Twitter é um recurso um pouco semelhante aos comentários do Facebook, mas não é comum se formar uma lista de respostas como se forma de comentários, tampouco isso aparece na página de quem fez a postagem inicial (é gerada uma conversa na timeline de quem respondeu, visível ao clicar em "visualizar conversa", abaixo da resposta). Já a opção de marcação de contatos é idêntica, no propósito e no modo de fazer (uitliza-se o @ antes do nome de usuário de quem se deseja marcar). Também é idêntico nome que se dá a lista de postagens por cada ator, a linha do tempo (timeline).

Além das mensagens curtas, outro grande diferencial do Twitter são as hashtags. Sempre precedidas por um \#, as hashtags são palavras-chave ou tópicos criadas pelos atores para categorizar um tweet. Através desse recurso, o Twitter contabiliza continuamente os as-

\footnotetext{
${ }^{8}$ O que está acontecendo? (Tradução do próprio site)
} 
suntos que mais estão sendo comentados no ambiente, num país específico ou no mundo inteiro, formando uma lista sempre atualizada, os trending topics. Outras opções são os favoritos onde cada ator marca os tweets prediletos, os quais ficam destacados.

Outros sites pontualmente utilizados nessa pesquisa são o Foursquare e o Youtube. O Foursquare foi desenvolvido especialmente para o acesso em aparelhos móveis como smartphones e tablets, tendo como funcionalidade principal a indicações de lugares para se visitar tendo como base a localização do usuário. Assim a partir da identificação da exata localização do ator (nem sempre tão exata assim, como descrevermos em uma das atividades realizadas), a plataforma disponibiliza um mapa onde demarca pontos próximos que o usuário poderia visitar, desde comércios, restaurantes, praças, pontos turísticos, criados e caracterizados (através de comentários) pelos próprios atores sociais no Foursquare. É possível criar contatos pela adição, como no Facebook, e visualizar as redes formadas. O perfil de cada ator tem informações dos "check-in" que ele fez, ou seja, os locais onde ele registrou presença e os badges $^{9}$ conquistados.

O Youtube, site de compartilhamento de vídeos mais famoso da internet, foi criado em fevereiro de 2005. Rapidamente se tornou uma febre na rede e possui cerca de meio $500 \mathrm{mi}$ lhões de usuários cadastrados, sendo que a visualização do conteúdo independe de cadastro. Possui recurso de avaliação dos vídeos (através da opção gostei, mais conhecida entre os atores como "joinha", semelhante ao curtir do Facebook, e de seu antônimo, o "não gostei”), espaço para comentários, avaliação e resposta a esses, além da opção “favoritos".

Embora essa plataforma permita a constituição de atores sociais por meio da criação de canais ${ }^{10}$ que podem se inscrever e receber inscrições de outros, constituindo laços sociais, isto é, os elementos básicos de uma rede social estão presentes nele, o Youtube não permite a visualização das redes formadas, então não pode ser considerado um SRS. Contudo, há uma forte ligação entre o Youtube e os principais SRS, permitindo a partilha de vídeos nesses direto do site. Vídeos mundialmente acessados, como o recente clipe da música Gangnam Style, vídeo mais assistido da rede, recebem milhões de comentários, grande parte deles em inglês. Isso serve como uma motivação para aprendizagem do idioma como forma de participação do

\footnotetext{
${ }^{9}$ Espécie de prêmios, selos, que os atores ganham de acordo com suas interações no site.

${ }^{10}$ Página de cada ator social no Youtube.
} 
discente em assuntos de interesse mundial e de interação com outras culturas e ao mesmo tempo, constitui-se em uma fonte de acesso ao idioma e suas variações em todo o mundo ${ }^{11}$, sem precisar sair da sala de aula.

Os recursos de cada SRS, junto à interação dos atores em cada ambiente, permitem a construção de uma linguagem própria para cada plataforma. Assim é comum dentro e fora das redes encontrar as seguintes expressões "idiomáticas" do ambiente: "te adicionei”, ou "se eu ganhar X curtidas", ou ainda "compartilha, por favor", ou "me marca lá", "me manda inbox ${ }^{12}$ ", "me segue no Twitter", "se inscrevam em meu canal”, "se gostou dá um joinha aqui embaixo do vídeo". Soma-se a isso a importação de linguagens de uma plataforma a outra, como o uso de hashtags no Facebook, por exemplo.

Como percebemos as redes sociais são ricas em possibilidade de interação e fluxo de informação, atraindo milhões de usuários. Não obstante, estão amplamente presentes no cotidiano escolar, seja nas conversas nos corredores ou na sala de professores na hora do intervalo, ou ainda na tela do celular de um aluno que mostra pro outro "quem acaba de curtir sua foto", todavia ainda são pouco apropriadas enquanto ferramenta de ensino apesar de sua evidente potencialidade para esse fim, por isso as mesmas têm sido alvo de pesquisa da Linguística Aplicada.

\section{CONSIDERAÇÕES FINAIS}

Ao longo do artigo detalhamos as características das redes sociais e sua representação nos ambientes digitais através das redes sociais na internet. Indicamos que o uso das redes sociais na internet constitui ferramentas produtivas para o ensino de língua estrangeira e que pode atrair os estudantes e levá-los ao conhecimento da língua, pois todo o processo interacional na internet se dá por meio da comunicação. Percebemos o quanto tais ferramentas são ricas em possibilidades de explorar as multisemioses, desenvolver os multiletramentos, estabelecer diálogos com aquilo que é diferente, a cultura do outro, além de permitir uma educa-

\footnotetext{
${ }^{11}$ Hoje em dia mais de dois terços dos falantes de inglês não se qualificam como nativos (CANAJARAH apud ARAGÃO, 2007).

${ }^{12}$ Expressão muito utilizada para mensagens privadas no Facebook.
} 
ção criativa e que promova alinhamentos necessários com as práticas sociais da contemporaneidade (BRASIl, 2006).

Num depoimento de uma aluna coletado em uma entrevista em vídeo ela declarou que essa metodologia é diferente porque enquanto no método tradicional as respostas vinham prontas, nessas redes eles tinham que "se virar" para descobrir e assim aprendiam mais. Isso porque cabe ao professor gerenciar as dinâmicas de aprendizagem, mas é o estudante quem conduz sua própria aprendizagem, que não pode ser controlada, tampouco definida ou possuir correspondência necessária ao ensino.

Desde o início optamos por planejarmos as aulas no decorrer do curso, tendo em vista os resultados já alcançados e a necessidade de aperfeiçoarmos constantemente a metodologia proposta, conforme prediz o próprio método da pesquisa-ação. As de uso das redes sociais com os alunos são todas construídas em parceria com a docente da turma, contudo temos visado o envolvimento cada vez maior dos discentes, a apropriação de práticas comuns entre eles, além do oferecimento de experiências novas.

Compreendemos também que, embora nesse trabalho o foco esteja nas redes sociais, existem diversas outras possibilidades que podem e precisam ser apropriadas pela escola conjuntamente para o ensino das diversas disciplinas a fim de provocar os multiletramentos entre os discentes. Isso sem perder de vista que os estudantes, assim como os professores, assumem diversos outros papeis fora do ambiente escolar, participam de vários grupos e são multidimensionais, ou seja, são indivíduos na coletividade de suas diversas redes sociais, dentro de sistemas complexos. Tais continuam sendo os nossos desafios.

\section{REFERÊNCIAS}

ARAGÃO, Rodrigo Camargo. Emoções e pesquisa narrativa: transformando experiências de aprendizagem. Revista Brasileira de Lingüística Aplicada, v. 8, n. 2, 2008.

ARAGÃO, R.C. Pesquisa e Geração de Tecnologia Educacional em Ilhéus e Itabuna. Estudos IAT, 2:190-205, 2012. 
ALEXANDRE, Carlos; PERES, Fernanda. A educação que motiva: o uso de rede social e jogos a favor da aprendizagem significativa. Hipertextus Revista Digital, 1(7):1-13, 2011.

BARABÁSI, Albert-Laszló. Linked: a ciência dos networks. São Paulo: Leopardo Editora, 2009.

BORBA, M.; ARAGÃO, R.C. 2012. Multiletramentos: novos desafios e práticas de linguagem na formação de professores de inglês. Polifonia, 19(25):223-240.

BRASIL. Orientações Curriculares para o Ensino Médio: linguagens, códigos e suas tecnologias. Secretaria de Educação Básica. Brasília: Ministério da Educação, 2006.

CASTELLS, Manuel. A galáxia da internet: reflexões sobre a internet, os negócios e a sociedade. Rio de Janeiro: Jorge Zahar Editor, 2003.

FARIA, Helen de Oliveira. Socializando e aprendendo: a incorporação da rede social Orkut ao ensino de língua inglesa. Belo Horizonte: Universidade Federal de Minas Gerais, 2010. [Dissertação]

LÉVY, Pierre. A inteligência coletiva: por uma antropologia do ciberespaço. São Paulo: Edições Loyola, 2007.

MUSSO, Pierre. A Filosofia da Rede. In: PARENTE, André. (Org.) Tramas da rede. Porto Alegre: Sulina, 2004.

OLIVEIRA, Ana Larissa Adorno Marciotto. A pesquisa-ação colaborativa e a prática docente localmente situada: dois estudos em perspectiva. Calidoscópio. São Leopoldo-RS: Unisinos, vol. 10, n. 1, p. 58-64, jan.-abr. 2012.

PRIMO, Alex. Interação mediada por computador. Porto Alegre: Sulina, 2007.

RECUERO, Raquel. Redes sociais na internet. Porto Alegre: Sulina, 2009.

SILVA, SOLIMAR PATRIOTA. Facebook como ambiente virtual de aprendizagem de língua inglesa no ensino superior. Educaonline, Rio de Janeiro, v. 7, n. 2., p. 1-16,mai./ago. 2013.

UMBELINA, Vanessa. Redes sociais: aliadas ou vilãs da educação? Hipertextus Revista Digital. n.9, Dez. 2012.

Recebido em: 1 de março de 2014.

Aceito em: 19 de março de 2014. 